\title{
Examination of Permanent Magnet Synchronous Motor
}

\author{
Muneeb Ahmad, Lakshmikant Bopche, Virendra Umale, Saurabh K Singh
}

\begin{abstract}
This paper focus on various loading conditions onthe Permanent Magnet Synchronous Motor and its application using field oriented control technique. Constant torqueapplication irrespective of speed isalso presented. This technique helps in lift and belt conveyors handling constant weight of material per unit time, in pumping and compressing and electric locos. Results of simulation shows that proposed system has high acceleration and deceleration rate with vector control,overall quick and dynamic response as well as excellent controlling ability. The vector control is a excellent technology for analysis and design of PMSM drive system. It provides designing and debugging for practical drive system. Modeling and different kinds of Permanent Magnet Synchronous Machines are studied and Simulation is carried out in Matlab and performance is studied at different operating conditions.
\end{abstract}

Keywords: Permanent magnet synchronous motor; field oriented control; loop current control; loop speed control.Abbreviations

$P$ Number of poles of stator poles

$i_{a,} i_{b}, i_{c} \quad$ stator phase currents (Amp)

$i_{d}, i_{q} d$ and $q$ axis currents (Amp)

$e_{a}, e_{b}, e_{c}$ back Emf (Volts)

$v_{a}, v_{b}, v_{c}$ phase voltages (volts)

$v_{d}, v_{q} \quad d \& q$ axis voltages (volts)

$v_{d c} \quad$ DC voltage (volts)

J Moment of Inertia, $\mathrm{kg}-\mathrm{m}^{2}$

$L_{a}, L_{b}, L_{c} \quad$ Self inductance of phase (Henrys)

$L_{a b} \quad$ Coupled inductance between $a$, and $b$ Phase (Henrys)

$L_{d}, L_{q} d \& q$ axis inductance (Henrys)

$\lambda_{a f}$ Mutual flux due to rotor magnet (Webers)

$\lambda_{d}, \lambda_{q} d \& q$ axis linkfluxes (Webers)

Revised Manuscript Received on July 22, 2019

Muneeb Ahma, Assistant Professor, Electrical Engg, PIGCE, , Nagpur, India

Lakshmikant Bopche, Assistant Professor, Electrical Engg, PIGCE, Nagpur, India

Virendra Umale, Assistant Professor, Electrical Engg, PIGCE, , Nagpur, India

Saurabh K Singh, Assistant Professor, Electrical Engg, SBJIET, ,

Nagpur, India
$R_{s}$ Resistance of stator winding

$L_{s} \quad$ Average inductance $\quad L_{s}=\left(L_{q}+L_{d}\right) / 2$

$L_{x}$ Inductance fluctuation $L_{x}=\left(L_{q}-L_{d}\right) / 2$

$\lambda_{m} \quad$ linkage flux due to magnet

$\theta_{r}$ Electrical angle between $d$-axis and $q$-axis

$\omega_{s}$ angular Synchronous speed $(\mathrm{Rad} / \mathrm{sec})$

$\omega_{r} \quad \omega_{r}=p \theta$, rotational speed $(\mathrm{rad} / \mathrm{sec})$

$T_{e}$ Motor developed torque in $(N-M)$

$\alpha$ and $\beta$ Stationary frame $\alpha$-axis and $\beta$-axis.

B friction coefficient $(\mathrm{N} / \mathrm{rad} / \mathrm{sec})$

\section{INTRODUCTION}

In servo applications PMSM can be used very efficiently. [1]-[3],. The PMSM required a sinusoidal back emf and sinusoidal stator current to produce constant torque. The PMSM considered in the paper has no damper bars and excitation through the permanent magnet instead of a field winding. This motor is mostly used in low and medium power applications like computers, robotics, variable speed applications, electric cars and constant torque application in various industries like steel mills and in transportation for material handling. [2], [3],[11].

Industry has demanded the need of simulation tools for permanent magnet motor and these system helped the process of developing new systems including motor drives, by reducing cost and time. Simulation tools have the capabilities of performing dynamic simulations of motor drives in a visual environment so as to facilitate the development of new systems. [7],[8],[10].

In permanent magnet machine the flux can be distribution radial and axially pattern. Surface permanent magnet and buried permanent magnet is a type of sinusoidal stator supply. In surface permanent magnet, permanent magnets are glued on the rotor surface using epoxy adhesive. Unlike in an interior permanent magnet the magnets are mounted inside the rotor [9], [12],[13] 
This paper shows the mathematical modeling, simulation of Permanent Magnet Synchronous Motor in MATLAB environment using vector control under different operations like i) stepwise rise in load ii) stepwise change in speed iii) reversal of speed, and simulation for electric vehicle load.

The paper is arranged as follows:

Section II is the modelling of the PMSM. Section III scalar followed by vector control method. Section IV.Various kinds of load. Section V. Electric transportation load, VI. System of drive. In section VII Results of Simulation. VIII. PMSM AC-6 system of drive. Section IX .Conclusion

Motor parameters are as under:

Power Rating $=1.1 \mathrm{KW}$

Armature Resistance $=2.875 \mathrm{ohm}$

Flux $=0.175$ weber

Direct Axis Inductance $=0.0085 \mathrm{H}$

Quadrature Axis Inductance $=0.0085 \mathrm{H}$

Moment of Inertia $=0.008 \mathrm{~kg}-\mathrm{m}^{\wedge} 2$

Number of Poles $=2$

\section{MODELLINGOF PMSM MACHINE}

The stator of are similar. The electromotive force generated by both the machines is same. The mathematical modelling of a PMSM has same to that of the wound rotor synchronous motor.The assumptions for derivation. [1]-[4]. Assumptions such as in the air gaps space harmonics are neglected due stator winding magneto motive force distribution. Reluctance air gap has sinusoidal varying component. Three phase balance supply. Saturation due to magnet is considered and iron losses are neglected. Absence of damper bars.[1],[9],[12]

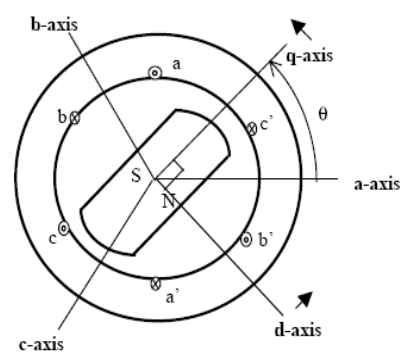

Fig 2.1. Permanent Magnet Synchronous Motor

Rotor reference frame equationof stator d, q [2], [3]

$V d=R s i d+p \lambda d+\omega r \lambda q$ $v q=R s i q+p \lambda q-\omega r \lambda d$

where

$\lambda q=\operatorname{Lqiq}(3)$

$\lambda d=\operatorname{Ldid}+\lambda a f(4)$

$\lambda a f$ is the magnet mutual flux linkage

The power input $\mathrm{p}_{\mathrm{i}}$ is indicated as

$P i=v a i a+v b i b+v c i c(5)$

in terms of $\mathrm{d}$, q variables

power input $=($ vdid + vqid $) / 2(6)$

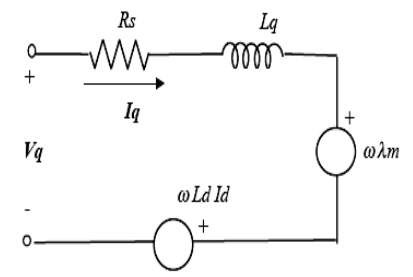

(a) q-axis circuit

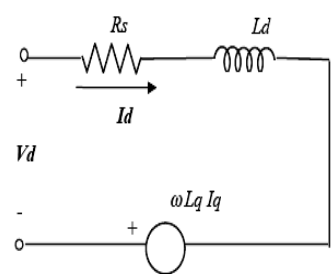

(b) d-axis circuit
Fig 2.2.Equivalent Circuit of a PM Synchronous Motor

Fig.2.2 indicates the circuit of IPM machine.Due to saturation magnetic circuits the current is increases. When $\mathrm{i}_{\mathrm{q}}$ is rises, the value of $\mathrm{L}_{\mathrm{q}}$ is fall and $\mathrm{L}_{\mathrm{m}}$ and $\mathrm{L}_{\mathrm{d}}$ are suffer to armature reaction. Here id is zero or negative value for operating conditions, saturation of $\mathrm{L}_{\mathrm{d}}$ is not occurs.[2],[3], [4].The torque Te generated by machine

$$
\mathrm{T}_{\mathrm{e}}=3 \mathrm{P}\left[\lambda_{\mathrm{m}} \mathrm{i}_{\mathrm{q}}+\left(\mathrm{L}_{\mathrm{d}}-\mathrm{L}_{\mathrm{q}}\right) \mathrm{i}_{\mathrm{d}} \mathrm{i}_{\mathrm{q}}\right] / 2
$$

Equation for the dynamics of machine

$T=T l+B \omega r+j p \omega r(8)$

Equation (7) showsthat the motor torque is consisting of two different operations. "the mutual reaction torque" occurring between $i_{q}$ and the permanent magnet and the "the torquedue to reluctance" due to the non uniform air gap.For constant flux operation when $i_{d}$ equals zero, the motor torque $\mathrm{T}_{\mathrm{e}}$

$$
\mathrm{T}_{\mathrm{e}}=3 \lambda_{\mathrm{m}} \mathrm{i}_{\mathrm{q}} / 2=\mathrm{k}_{\mathrm{t}} \mathrm{i}_{\mathrm{q}}
$$

Where $\mathrm{k}_{\mathrm{t}}$ is themotor torque constant. This torque equation is similar that of the dc machine and provides ease to control. [2]-[3].

$\mathrm{v}_{\mathrm{d}}$ and $\mathrm{v}_{\mathrm{q}}$ are obtained from $\mathrm{v}_{\mathrm{a}}, \mathrm{v}_{\mathrm{b}}$, and $\mathrm{v}_{\mathrm{c}}$ with park's transformation as given below.[2-6]

$$
\left[\begin{array}{l}
v q \\
v d \\
v 0
\end{array}\right]=2 / 3\left[\begin{array}{cc}
\cos \theta & \cos \left(\theta-\frac{2 \pi}{3}\right) \cos \left(\theta+\frac{2 \pi}{3}\right) \\
\sin \theta & \sin \left(\theta-\frac{2 \pi}{3}\right) \sin \left(\theta+\frac{2 \pi}{3}\right) \\
\frac{1}{2} \frac{1}{2} \frac{1}{2}
\end{array}\right]\left[\begin{array}{l}
v a \\
v b \\
v c
\end{array}\right]
$$

The zero sequence components $\mathrm{v}_{\mathrm{o}}$ under balanced three phase system is always 
zero. Since it is a linear transformation a, b, c variables are obtained from $\mathrm{d}, \mathrm{q}$ variables through the inverse of the park's transformation as given below.

$$
\left[\begin{array}{l}
v a \\
v b \\
v c
\end{array}\right]=\left[\begin{array}{ccc}
\cos \theta & \sin \theta & 1 \\
\cos \left(\theta-\frac{2 \pi}{3}\right) \sin \left(\theta-\frac{2 \pi}{3}\right) & 1 \\
\cos \left(\theta+\frac{2 \pi}{3}\right) \sin \left(\theta-\frac{2 \pi}{3}\right) & 1
\end{array}\right]\left[\begin{array}{l}
v d \\
v q \\
v o
\end{array}\right]
$$

Where $\theta$ is the position of rotor. $\mathrm{L}_{\mathrm{d}}>\mathrm{L}_{\mathrm{q}}, \mathrm{i}_{\mathrm{d}}$ must be negative.

\section{SCALAR AND VECTOR CONTROL}

In scalar control the magnitude of variables is control and scalar control is eas to implement. Coupling effect causes the poor dynamic response and the system is easily suffer instability because of a high order fifth harmonic system effect, i.e. if torque is increased by increasing the slip (frequency), the flux tend to decrease and flux variation is always sluggish. For controlling the flux additional voltage is required (Boost voltage).The temporary drop in flux decreases the torque sensitivity with slip and increases the time response. This problem is overcome by using the Field oriented control method. [712]

In field oriented control, magnitude and phase alignment both vector variables can be control. Vector control drive operates same as a separately excited direct current motor drive because of performance is like direct current machine and vector control is known as decoupling control. Vector control methodology can apply to induction as well as PMSM drives. [8], [12].both torque and field component is orthogonal in separately excited direct current machine and hence independently control. The electric torque equation of a separately excited direct current machine as given below

$\mathrm{T}_{\mathrm{e}}=\mathrm{K}_{\mathrm{t}} \psi_{\mathrm{f}} \psi_{\mathrm{a}}=\mathrm{K}_{\mathrm{t}} \mathrm{I}_{\mathrm{a}} \mathrm{I}_{\mathrm{f}}$

Where $\mathrm{k}_{\mathrm{t}}=$ motor torque constant, $\mathrm{i}_{\mathrm{a}}=$ Torque component (armature current), $\mathrm{i}_{\mathrm{f}}=$ Field component (field current)

This vector control technique is somewhat similar to that of permanent magnet synchronous motor vector control, except, in vector control of PMSM for maximum torque sensitivity with the stator current, we can set $i_{d}=0$ and $i_{a}=$ $\mathrm{i}_{\mathrm{qs}}$. The slip frequency $\omega_{\mathrm{sl}}=0$ because the machine runs at synchronous speed $\omega_{\mathrm{e}}$. The magnetizing current $\mathrm{i}_{\mathrm{ds}}=0$ because rotor flux is produced by permanent magnet [8], [12]. This condition is also gives a minimum inverter power rating. Equation (3) and (4) can be represented in phasor diagram as given below in fig.3.2.

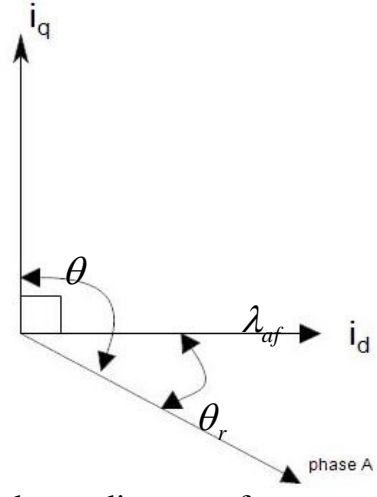

Fig.3.2. phasor diagram of vector controller

\section{DIFFERENT TYPES OF LOAD}

The various kinds of electrical loads which include constant type load torque: e.g. Machine tools, Extruders, Mixers, Lift machines, Positive displacement pumps and compressors. Torque proportional to square of the speed e.g. electric fan type load, pumps and propellers. [6],[12]. Constant power type load: The power remains constant while the torque varies. The torque is inversely proportional to speed. This includes electric vehicle drives, it requires more starting torque at low speed for initial acceleration, then a reduced torque when at running speed.[3],[4]

\section{ELECTRIC VEHICLE LOAD}

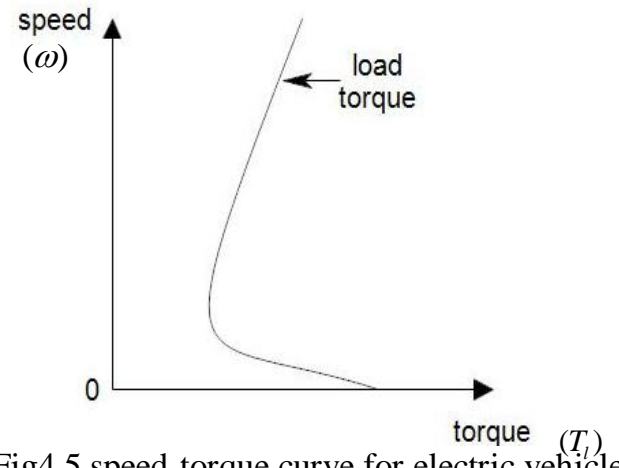

Fig4.5.speed-torque curve for electric vehicle

Fig4.5 shows the torque-speed curve of an electric vehicle load. The stiction is large near zero speed because of its heavy weight and total torque is due to stiction. The stiction may loss atsome finite speed and then windage and viscous friction loss is dominant. Because of high stiction and need for accelerating a heavy mass, the initial torque required for staring a electric vehicle is much larger than required to run it at full speed.[12],[5]

\section{DRIVE SYSTEM}

The main component of drive system consist of permanent magnet synchronous machine, speed and position feedback, a PWM inverter and signal builder for loading. A 3-phase motor rated $1.1 \mathrm{kw}, 220 \mathrm{~V}$, and $3000 \mathrm{rpm}$ is fed by Pulse width modulated inverter [12], [13]. Its output voltage provided through controlled source block before given to the stator windings. 
The load torque mounted to the rotor shaft is build with the help of signal builder from MATLAB library. Using signal builder we can construct different types of load torque curve. Two control loops are used. To control the motor currents inner loop is used. To controls the motor speed outer loop is used. The $\mathrm{id}=0$ controlling methodology is used [1], [2].

\section{SIMULATION RESULTS}

The proportional and integral controller is used to control the speed and $\mathrm{d}-\mathrm{q}$ axis current, id=0 control method is using for PMSM. The model runs in MATLAB using vector control of PMSM.

At starting the torque increases rapidly initial point. During this period, the speed is also rises linearly due to vector control and the commanded torque is equal to the maximum capability of the motor. This shows that machine speed up in shortest possible time. Fig.8 (a), 8(b), 8(c) shows the different operating condition of PMSM using vector control methodology in Matlab
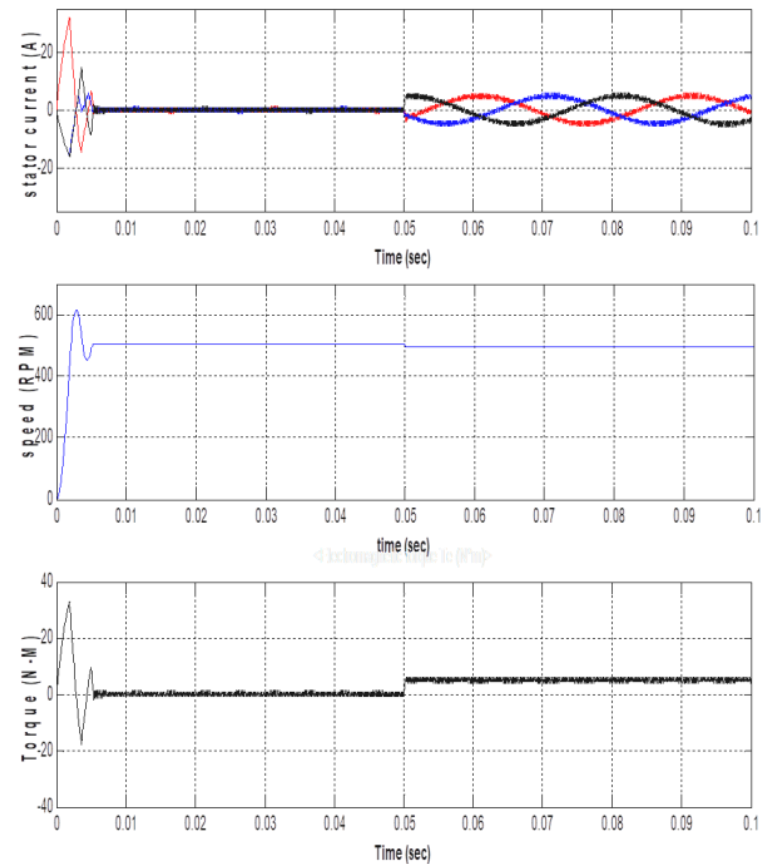

Fig 8 (a).Step rise in load

It is seen that the current and torque response time is minimum and very small fluctuation in speed. It is seen that at stable operation the speed is remains constant and current maintain a good sinusoidal nature shown in fig 8(a). In figure 8(a) shows at the time of starting motor is running at no load with zero load torque so it is called as no load operation but at $\mathrm{t}=0.05$ sec step changed in load from no load to a torque of $6 \mathrm{~N}$-M.the torque is very high but the same time motor achieve the reference speed due to vector control. The system runs very smoothly.
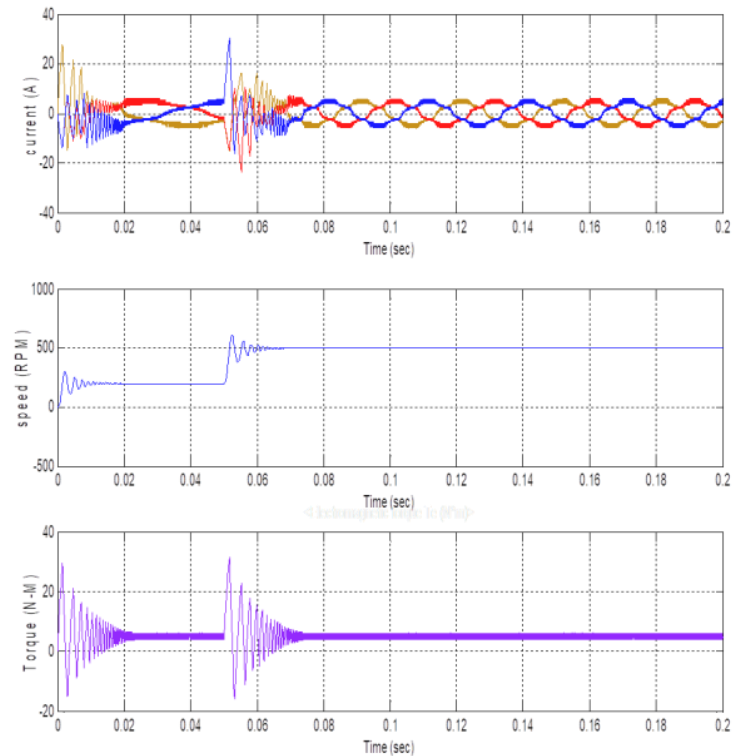

Fig 8(b). Step change in reference speed

From result it is seen that speed can be change from reference speed to desired speed by changing the frequency of supply. The reference speed is $200 \mathrm{rpm}$ after $0.05 \mathrm{sec}$ the supply frequency is changed and motor speed up to $500 \mathrm{rpm}$ and from figure 8(b) it is seen than sinusoidal current and speed response is smooth. From result we can see that speed can be change from reference speed to desired speed by changing the frequency of supply. The reference speed is $200 \mathrm{rpm}$ after $0.05 \mathrm{sec}$ the supply frequency is changed so as to achieve the 500 rpm and from figure 8(b): current is sinusoidal and speed response is very smooth
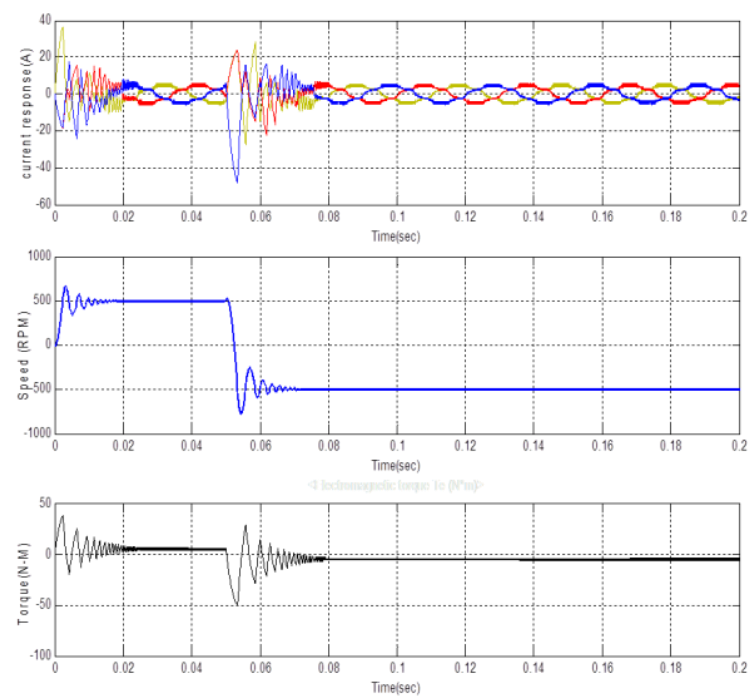

Fig 8 (c).Speed Reversal

From figure 8 (c) the speed of PMSM can be changed by changing the phase sequence of the supply system, from R-Y-B to R-B-Y.

At starting reference speed is $500 \mathrm{rpm}$ but at $0.05 \mathrm{sec}$ speed becomes $-500 \mathrm{rpm}$. At the same time the phase sequence of supply is also change as shown in current waveform. 
Fig.8 (d), results shows that system has rapid acceleration and retardation and from fig.8 (c), plugging reversal is also possible which is desired characteristics for Electrical vehicles; motor can run stably and has excellent static as well as dynamic performance which is more efficient for Electric Vehicle. In each operating condition current and torque response time is very small and very small fluctuation in speed. One can see that the during steady state operation the speed is constant and current maintain a good sinusoidal waveform.

\section{AC6 - PERMANENT MAGNETSYNCHRONOUS MOTOR DRIVE}

The permanent magnet synchronous motor is supplied by a pulse width modulated voltage source inverter, which is built using a Universal Bridge Block. The speed control loop uses a proportional and integral controller to produce the flux and torque references for the vector control block. The vector control block measures the reference line currents of the machine corresponding to the flux and torque references and then supply to the motor, using a threephase current controller. Stator current, speed, and torque signals output of this block.

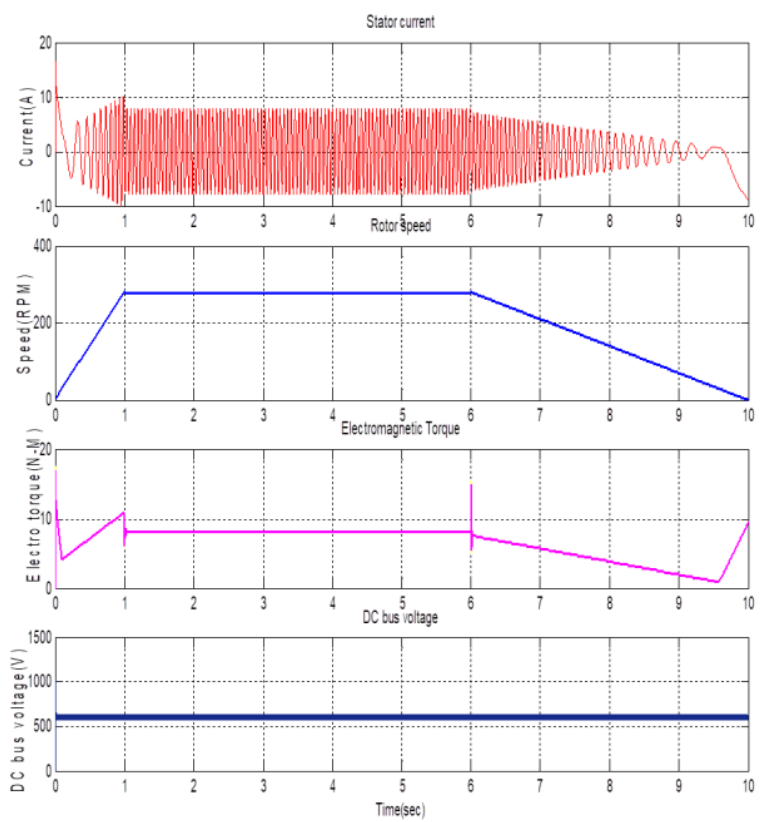

Fig.9 (a) Simulation result for electric vehicle load

From figure 9 (a), stator current, the rotor speed, the motor torque and the bus voltage on the scope. The set point of speed and the torque are display.

At starting $\mathrm{t}=0$ set speed is $300 \mathrm{rpm}$, it shows that speed followed precisely the acceleration ramp it is called as acceleration

At $\mathrm{t}=1 \mathrm{sec}$, the rated load torque is applied to the motor. One can observe a little disturbance in the motor speed, which stabilizes rapidly.
At $\mathrm{t}=6 \mathrm{sec}$, set point of speed has changed to zero value. The speed falls down to zero value following precisely the deceleration ramp. This time is called as retardation. From this result one can say that system exhibit speed-torque curve for electric vehicle hence this drive system is suitable for electric vehicle application.

\section{CONCLUSION}

This paper has presented modelling, simulation, and field oriented control of permanent magnet synchronous machine under different operating condition and suitable for electric vehicles applications. Since vector control transform the permanent magnet synchronous motor to an equivalent separately excited direct current machine. The result indicates that the small and large signal responses are very similar. The large and small signal speed response is same. Results of Simulation indicates that system has rapid acceleration and retardation and it can run smoothly and has good static as well as dynamic responses which is more efficient for electric traction application and Electric Vehicle.

The vector control is a excellent technology for analysis and design of PMSM drive system. It provides designing and debugging for practical drive system.

Final conclusion is that Modelling and different types of permanent magnet synchronous motor is studied and Simulation is carried out in Matlab and performance is studied at various operating conditions. It is found that permanent magnet synchronous motor can be used for variety of application under different operating condition due to high power, high torque, and high dynamic response.

\section{REFERENCES}

[1]Zamani, H.Karimi, M.H.Kanzi, K.Vasheghani, Q. "Vector control of Counter-Rotating Permanent Magnet Synchronous Motor for underwater propulsion application".Power Electronics, Drive Systems and Technologies Conference (PEDSTC), $20134^{\text {th }}$.ISBN: 978-14673-4481-4, pp no: $44-48$.

[2] Tiecheng Sun, Ce Liu , Ningbo Lu , Deyan Gao. "Design of PMSM vector control system based on TMS320F2812 DSP". Power Electronics and Motion Control Conference (IPEMC), 2012 7th International (Volume: 4),ISBN: 978-1-4577-2085-7, pp no.2602 2606.

[3]Kiran Boby, Prof.Acy M Kottalil, N.P.Ananthamoorthy, "Mathematical Modelling of PMSM Vector Control System Based on SVPWM with PI Controller Using MATLAB'.International Journal of Advanced Research in Electrical, Electronics and Instrumentation Engineering Vol. 2, Issue 1, January 2013.

[4] Zhang Haigang; Qian Weiguo; Wu Yanxiang; Gan Shihong; Yu Yuan; "Modeling and simulation of the permanent- magnet synchronous motor drive". Uncertainty Reasoning and Knowledge Engineering (URKE), International conference-2011, vol no: 2. pp.256-260.

[5] P. Pillay and Krishnan, "Modeling analysis and simulation of a high performance vector controlled, permanent magnet synchronous motor drive ', presented at IEEE, IAS Annual meeting, Atlanta , pp.380-390, Oct.1987.

[6] P.Pillay and R. Krishnan, "Modeling, simulation and analysis of permanent magnet motor drives, Part I: The permanent magnet synchronous motor drive', Industry application, IEEE Transactions on vol.25.no.2, pp. 265-273, March/April 1989. 
[7] Zhanghui Zhang, Jiao Shu, "Matlab-based permanent magnet synchronous motor vector control simulation". Computer Science and Information Technology (ICCSI), 2011, $3^{\text {rd }}$ IEEE International conference, vol no: 9, pp.539-542.

[8] M. Zeraoulia, and et al, "Electric motor drive selection issues for HEV propulsion systems: A comparative study," IEEE Trans. Vehicular Tech., vol. 55, pp.1756-1763, Nov. 2006.

[9]S. Wu, L. Song, and S. Cui, "Study on improving the performance of Permanent magnet wheel motor for the electric vehicle application," IEEE Trans. Magn., vol. 43, pp. 438-442, Jan 2007.

[10] Wang Yichao, Liu Jun, "Research on the load characteristics of permanent magnet synchronous motor". Digital Manufacturing and Automation (ICDMA), 2011, Second International Conference, pp.1034-1037.

[11] Muneeb Ahmad and P.Debre, "Analysis of permanent magnet synchronous motor under different operating consition using vector control in MATLB, 2013, IJIREEICE, vol no:1, issue-3, 2013.

[12] B.K. Bose, Modern power electronics and AC drives Prentice Hall of India. Pvt Ltd, 2010

[13] R. Krishnan, "Electric motor drives-Modeling, Analysis and Control", Prentice Hall of India. Pvt Ltd. 2005.. 